\title{
Article \\ Theoretical and Experimental Study on Assessment of Flow-Mediated Dilatation Using the Cuff Method in Brachial Arteries
}

\author{
Jia-Jung Wang ${ }^{1}$, Shing-Hong Liu ${ }^{2, *} \mathbb{(}$, Yong-Hong Pan ${ }^{1}$, Wei-Kung Tseng ${ }^{3}$ and Wenxi Chen ${ }^{4}(\mathbb{C}$ \\ 1 Department of Biomedical Engineering, I-Shou University, Kaohsiung 824, Taiwan; \\ wangjj@isu.edu.tw (J.-J.W.); weapon4771@gmail.com (Y.-H.P.) \\ 2 Department of Computer Science and Information Engineering, Chaoyang University of Technology, \\ Taichung 413, Taiwan \\ 3 Department of Cardiology, E-Da Hospital, Kaohsiung 824, Taiwan; tsengarthur@gmail.com \\ 4 Biomedical Information Engineering Laboratory, The University of Aizu, Aizu-Wakamatsu 965-8580, \\ Fukushima, Japan; wenxi@u-aizu.ac.jp \\ * Correspondence: shliu@cyut.edu.tw; Tel.: +886-4-233230000-7811
}

check for

updates

Citation: Wang, J.-J.; Liu, S.-H.; Pan, Y.-H.; Tseng, W.-K.; Chen, W. Theoretical and Experimental Study on Assessment of Flow-Mediated

Dilatation Using the Cuff Method in Brachial Arteries. Electronics 2022, 11, 351. https://doi.org/10.3390/ electronics11030351

Academic Editor: Antonio Lanata

Received: 25 November 2021

Accepted: 19 January 2022

Published: 24 January 2022

Publisher's Note: MDPI stays neutral with regard to jurisdictional claims in published maps and institutional affiliations.

Copyright: (C) 2022 by the authors. Licensee MDPI, Basel, Switzerland. This article is an open access article distributed under the terms and conditions of the Creative Commons Attribution (CC BY) license (https:// creativecommons.org/licenses/by/ $4.0 /)$.

\begin{abstract}
Endothelial dysfunction has been shown to be an important risk factor in the pathogenesis of atherosclerosis, hypertension, and heart failure. The flow-mediated vasodilation (FMD) of the peripheral arteries is an endothelium-dependent function, which is assessed by measuring the diameter change in the brachial artery before and after ischemic stress. Brachial-artery ultrasound scanning (BAUS) is the gold standard for assessing the FMD in clinical practice. However, ultrasonography requires an operator or physician with a professional training to perform accurate measurement of the diameter of the brachial artery. Thus, some studies have used the cuff method to measure the FMD in percentage, the value of which is significantly larger than that using BAUS. The goal of this study was to explore this phenomenon. We explain the interaction between the volume changes (oscillation magnitudes in volume due to cardiac pulsations) of the artery and cuff bladder under different transmural pressures when a sphygmomanometer is wrapped around an upper arm. The compliance of the cuff bladder would be of a fixed value when the cuff pressure is low. The cuff-volume change could be replaced with a cuff-pressure change (oscillation magnitude in cuff pressure due to cardiac pulsation). With the cuff method, the FMD ${ }_{c}$ could be assessed with pressure changes. Then, an inequality formula regarding FMD values by both BAUS (FMD $\mathrm{u})$ and the cuff method $\left(\mathrm{FMD}_{\mathrm{C}}\right)$ was derived; $\mathrm{FMD}_{\mathrm{c}}>2 * \mathrm{FMD}_{\mathrm{u}}+\mathrm{FMD}_{\mathrm{u}}{ }^{2}$. In order to experimentally verify this inequality formula, fifty-one subjects, including thirty-eight healthy adults and thirteen patients with hypertension, participated in this study. The systolic and diastolic diameters of their brachial arteries and cuff-pressure changes due to cardiac pulsations were separately measured by BAUS and a pressure sensor before and after an ischemic stress. The results showed that $\mathrm{FMD}_{\mathrm{u}}$ and $\mathrm{FMD}_{\mathrm{c}}$ were $8.1 \pm 4.3 \%$ and $121.6 \pm 48.6 \%$ in the healthy group and $4.5 \pm 1.1 \%$ and $55.2 \pm 22.8 \%$ in the patient group, respectively. Thus, the experimental findings comply with the theoretically derived inequality formula.
\end{abstract}

Keywords: flow-mediated vasodilatation; endothelial dysfunction; cuff method; brachial-artery ultrasound scanning

\section{Introduction}

Atherosclerosis is a chronic condition caused by the stiffness of arteries by way of the buildup of plaques, the main classical risk factors of which include hypertension, diabetes mellitus, dyslipidemia, and smoking [1]. Hypercholesterolemia is one of the main sources of atherosclerosis. A plasma cholesterol level of more than $200 \mathrm{mg} / \mathrm{dL}$ is diagnosed as hypercholesterolemia [2]. Low-density lipoprotein cholesterol (LDL-c) in 
the arterial wall causes endothelial dysfunction of artery. Circulating monocytes cohere into the endothelial cells that express adhesion molecules, such as vascular adhesion molecule-1 and selectins, and consequently migrate via diapedesis in the subendothelial space [3]. LDL-c molecules in the subendothelial space are oxidized and changed into a strong chemoattractant. These processes promote lipid accumulation, scarring, and inflammation in the vascular wall. Clinical sequelae of atherosclerosis lead to vascular wall thickening, luminal stenosis, calcification, and, in some cases, thrombosis; lipid instability causes coronary artery syndrome $[4,5]$. Atherosclerosis appears earliest in the aorta during fetal life. In the second decade of life, it appears in the coronary arteries. In the third decade, it appears in the cerebral arteries [6]. The development of lesions often happens at predisposed sites, such as branch points, proximal parts, and curvatures of smaller vessels.

Vascular endothelial dysfunction represents an initial stage of atherosclerosis, which is considered as a metabolic abnormality of the vessel wall, including inflammation and oxidative stress. The healthy endothelial cells not only constitute the vessel wall but can also respond to the wide range of physical and chemical factors that regulate vascular tone, cellular adhesion, thromboresistance, smooth muscle cell proliferation, and vessel wall inflammation [7]. Endothelium-dependent relaxation has been shown to be mediated by the nitric oxide (NO) [8]. Circulating levels of nitrites and nitrosylated proteins in part reflect the endothelial generation of NO. However, these levels are difficult to measure and may not always represent endothelial NO production [9]. During the last decade, the flow-mediated vasodilation (FMD) method has been developed to assess the endothelium, dependent on the blood flow of forearm arteries by high-resolution ultrasonography or plethysmography using the occlusion technique $[10,11]$. Forearm blood flow is influenced mainly by the resistance of arteries. This resistance could be considered as the function of vasodilation. According to the guideline of FMD measurement by the ultrasonography using occlusion techniques, the brachial artery will be occluded by a sphygmomanometer cuff, which is inflated to a pressure level $50 \mathrm{mmHg}$ above the subject's systolic blood pressure (SBP) to block arterial blood flow for at least five minutes and to cause an episode of ischemic stress [10]. Before and after ischemic stress, the diameters of brachial arteries are measured. The FMD ratio is defined as the changed ratio of arterial diameters.

Brachial artery ultrasound scanning (BAUS) is the most commonly used method in FMD measurement [11,12]. However, a physician's training in the principles and skills of ultrasonography affects the accuracy of the FMD measurement [13]. In recent years, the measurement of the peripheral vasodilator response with fingertip peripheral arterial tonometry (PAT) has been used to assess the endothelial dysfunction [14,15]. The fingertip PAT uses transmission photoplethysmography (PPG) to measure the change in blood flow in the finger. Although the fingertip PAT signal is affected by various local, systemic, and environmental factors, this signal is also affected by the bioavailability of NO.

Kuvin et al. compared the relation between FMD as a \%, measured by PAT and BAUS, for subjects with high risk of endothelium dysfunction. Their results showed a significant correlation between the two FMD values [16]. Hashimoto et al. used BAUS to assess the FMD of 17 volunteer women in three different phases of one menstrual cycle-the menstrual, follicular, and luteal phases [17]. The FMD\% in the menstrual and luteal phases were significantly different. Liu et al. developed a cuff method to measure the FMD ratio in which a sphygmomanometer cuff, wrapped around the upper arm, could detect the volume variation of one brachial arterial segment of interest due to the pulsatile blood flow [18]. They assessed the performance of this method by measuring the FMD ratios for 26 volunteer women in three different phases of two menstrual cycles. Their results were consistent with those results of Hashimoto et al. [17]. However, in the study of Hashimoto et al., the BAUSbased FMD $\%$ in menstrual and luteal phases were $11.22 \pm 0.58 \%$ and $17.53 \pm 0.74 \%$ after a 5 min episode of arterial occlusion (250 $\mathrm{mmHg})$, respectively [17]. Furthermore, based on the transferred volume from the cuff pressure, Liu et al. indicated that the cuff-based FMD $\%$ in the menstrual and luteal phases were $101.9 \pm 45.5 \%$ and $137.5 \pm 62.1 \%$ after a 5 min episode of arterial occlusion (systolic pressure $+50 \mathrm{mmHg}$ ), respectively [18]. 
We found that the values of FMD\% measured by the cuff method were significantly larger than that by BAUS. The goal of this study is to verify the authenticity of this phenomenon. The inequality formula of FMD\% measured by the BAUS and cuff methods is derived. We explain the interaction between the volume changes (oscillation magnitudes in volume due to cardiac pulsations) of an artery and the cuff bladder under different transmural pressures when a sphygmomanometer cuff is wrapped around the upper arm. If the compliance (defined as the delta volume divided by the delta pressure) of a cuff bladder is considered to be constant, the cuff-volume change due to cardiac pulsation will be replaced with the cuff-pressure change due to the pulsation. Thus, in the cuff method, the FMD $\%$ is assessed with cuff-pressure changes before and after the ischemic stress. Fifty-one subjects, including thirty-eight healthy adults and thirteen patients with hypertension, participated this study for FMD\% measurements by BAUS and the cuff method. Moreover, we also simultaneously evaluated peripheral vasodilator response with the transmission PPG in the finger. The results show that the measured data comply with the proposed inequality formula considerably.

This paper is organized as follows. Section 2 describes the theorem and measurement method for the FMD\% assessed by the ultrasonography, cuff method, and PPG. Section 3 presents the experimental results of BAUS and the cuff method. The results are discussed in Section 4. Finally, the conclusions are drawn in Section 5.

\section{Materials and Methods}

In this study, three FMDs in \% were measured by the ultrasonography, cuff method and PPG, respectively. For the cuff method, a sphygmomanometer cuff wrapped around a subject's upper arm was used not only to perform the ischemic stress of the brachial artery but also sense the cuff-pressure changes due to cardiac pulsations before and after the ischemic stress. According to the interaction between the brachial artery and cuff bladder, we derived the relation between the two FMD values assessed by the BAUS and cuff method, respectively.

\subsection{Assessment of FMD Using the Ultrasonography}

The FMD assessed by BAUS (FMD $\left.{ }_{u}\right)$ is defined as

$$
\mathrm{FMD}_{\mathrm{u}}=\frac{\mathrm{D}_{\mathrm{H}, \text { max }}-\mathrm{D}_{\mathrm{B}, \text { max }}}{\mathrm{D}_{\mathrm{B}, \max }},
$$

where $\mathrm{D}_{\mathrm{B}, \mathrm{max}}$ is the maximum diameter of the brachial artery under the systolic pressure before the ischemic stress, which is considered as the baseline, and $\mathrm{D}_{\mathrm{H}, \max }$ is the maximum diameter of the brachial artery under the systolic pressure after ischemic stress (phase of hyperemia reaction) [11]. $\mathrm{D}_{\mathrm{B}, \max }$ and $\mathrm{D}_{\mathrm{H}, \max }$ are attained at the physician's discretion.

\subsection{Assessment of FMD Using Sphygmomanometer Cuff}

According to a study by Liu et al. [18], the FMD assessed by the change in the cuff volume due to arterial pulsation when the cuff is wrapped around an upper arm $\left(\mathrm{FMD}_{\mathrm{c}}\right)$ is defined as

$$
\mathrm{FMD}_{\mathrm{c}}=\frac{\Delta \mathrm{V}_{\mathrm{c}, \mathrm{H}}-\Delta \mathrm{V}_{\mathrm{c}, \mathrm{B}}}{\Delta \mathrm{V}_{\mathrm{c}, \mathrm{B}}}
$$

where $\Delta \mathrm{V}_{\mathrm{c}, \mathrm{B}}, \Delta \mathrm{V}_{\mathrm{c}, \mathrm{H}}$ are the changes in the cuff volume due to the pulsatile nature of arterial blood pressure (oscillating between the systolic and diastolic values) during the baseline and hyperemia reaction phases.

\subsection{Assessment of FMD Using the Photoplethysmography}

Transmission PPG uses a light-emitting diode (LED) to generate low-intensity infrared (or other wavelengths) light on the skin, and a photo detector to pick up the transmitted light after passing through the tissue segment and being absorbed mainly by the red cells in both arterial and venous blood. For the transmission PPG, non-absorbed light will be 
transmitted and detected by a photo diode. The LED and photo diode are placed on the opposite sides of the finger. Thus, the PPG signal shows the changes in blood volume, although it cannot be used to quantify the amount of blood. When the PPG probe, fingertip clip, is placed on the finger, the plethysmogram of the arterioles can be detected. Thus, the FMD assessed by the PPG $\left(\right.$ FMD $\left._{p}\right)$ is defined as

$$
\mathrm{FMD}_{\mathrm{p}}=\frac{\Delta \mathrm{V}_{\mathrm{p}, \mathrm{H}}-\Delta \mathrm{V}_{\mathrm{p}, \mathrm{B}}}{\Delta \mathrm{V}_{\mathrm{p}, \mathrm{B}}},
$$

where $\Delta \mathrm{V}_{\mathrm{p}, \mathrm{B}}, \Delta \mathrm{V}_{\mathrm{p}, \mathrm{H}}$ are the amplitudes (voltages) of the PPG signal due to the pulsatile nature of arterial blood pressure (oscillating between the systolic and diastolic values) during the baseline and hyperemia reaction phases. To reduce the effect of motion artifacts on $\Delta \mathrm{V}_{\mathrm{p}, \mathrm{H}}$, the amplitudes of three contiguous pulses of the PPG signal are averaged as $\Delta \mathrm{V}_{\mathrm{p}, \mathrm{H}}$, which are manually selected in a $5 \mathrm{~s}$ interval centered at the $\mathrm{D}_{\mathrm{H}, \max }$ time for the hyperemic phase. Moreover, the median pulse corresponds to the maximal magnitude. Similarly, to increase the stability of $\Delta \mathrm{V}_{\mathrm{p}, \mathrm{B}}$, three contiguous pulses with most coincident amplitudes are averaged as $\Delta \mathrm{V}_{\mathrm{p}, \mathrm{B}}$, which are manually selected in a $20 \mathrm{~s}$ interval preceding the ischemia, for baseline phase.

\subsection{Cuff Model}

As shown in Figure 1, an air cuff bladder with length $\mathrm{L}$ is wrapped around a subject's upper arm. The air pressure $\left(\mathrm{P}_{\mathrm{c}}\right)$ and volume $\left(\mathrm{V}_{\mathrm{c}}\right)$ inside the expanded cuff bladder vary because the blood pressure $\left(\mathrm{P}_{\mathrm{a}}\right)$ and volume $\left(\mathrm{V}_{\mathrm{a}}\right)$ of the enclosed brachial artery are varied by the pulsatile blood flow. For an L-length brachial arterial segment, a sigmoidal relationship (red curve) between its $\mathrm{P}_{\mathrm{a}}$ and $\mathrm{V}_{\mathrm{a}}$ is shown in Figure 2a. The pulse pressure $\Delta \mathrm{P}_{\mathrm{a}}$ is the systolic pressure $\left(\mathrm{P}_{\mathrm{s}}\right)$ minus diastolic pressure $\left(\mathrm{P}_{\mathrm{d}}\right)$. The volume change of the artery $\left(\Delta V_{a}\right)$ due to cardiac pulsation is the $V_{a, s}$ minus $V_{a, d}$, where $V_{a, s}$ and $V_{a, d}$ are the volumes of the artery under the systolic and diastolic blood pressures, respectively. We know that $\Delta \mathrm{V}_{\mathrm{a}}$ has an effect on the cuff bladder. According to the ideal gas formula, $\mathrm{P}_{\mathrm{c}} \mathrm{V}_{\mathrm{c}}=\mathrm{nRT}$ exists in the air cuff bladder, where $\mathrm{n}$ is the number of gas molecular particles inside the cuff, $\mathrm{T}$ is the absolute temperature in the cuff bladder, and $\mathrm{R}$ is a constant. When the cuff pressure is held under a constant temperature, the value of $P_{c}$ multiplied by $V_{c}$ is a constant. In other words, $\mathrm{P}_{\mathrm{c}}$ is inversely proportional to $\mathrm{V}_{\mathrm{c}}$. Such a relationship (purple curve) between $P_{c}$ and $V_{c}$ is shown in Figure $2 b$. The relation of volume changes in the artery and cuff bladder due to cardiac pulsations can be expressed as

$$
\Delta \mathrm{V}_{\mathrm{c}}=\alpha \Delta \mathrm{V}_{\mathrm{a}},
$$

where $\alpha$ is the proportionality constant between 0 and $1 . \Delta \mathrm{V}_{\mathrm{c}}$ is $\mathrm{V}_{\mathrm{c}, \mathrm{d}}$ minus $\mathrm{V}_{\mathrm{c}, \mathrm{s}}$, where $\mathrm{V}_{\mathrm{c}, \mathrm{d}}$ and $\mathrm{V}_{\mathrm{c}, \mathrm{s}}$ are the volumes of the cuff under the diastolic and systolic pressures in a pulse, respectively. When the arterial volume becomes large under the systolic pressure, the cuff volume will be pushed by the arterial volume and become small. On the other hand, when the arterial volume becomes small under the diastolic pressure, the cuff volume will extend and become large. The change in cuff pressure $\left(\Delta \mathrm{P}_{\mathrm{c}}\right)$ is affected by $\Delta \mathrm{V}_{\mathrm{c}}$. $\mathrm{C}_{\mathrm{c}}$ is the compliance of the air cuff bladder.

The compliance of the cuff bladder $\mathrm{C}_{\mathrm{c}}\left(\mathrm{P}_{\mathrm{c}}\right)$, depending on the $\mathrm{P}_{\mathrm{c}}$, is defined as

$$
\mathrm{C}_{\mathrm{c}}\left(\mathrm{P}_{\mathrm{c}}\right)=\frac{\mathrm{dV}_{\mathrm{c}}}{\mathrm{dP}_{\mathrm{c}}} .
$$

When the cuff bladder is maintained at a low pressure (about $40 \mathrm{mmHg}$ ) and $\Delta \mathrm{V}_{\mathrm{c}}$ and $\Delta \mathrm{P}_{\mathrm{c}}$ are very small (about $0.1 \mathrm{~mL}$ and $2 \mathrm{mmHg}$ ) $[19,20]$, the average compliance of the cuff 
bladder will be derived from the ratio between $\Delta \mathrm{V}_{\mathrm{c}}$ and $\Delta \mathrm{P}_{\mathrm{c}}$ when the cuff is pressurized at that such small range of pressure levels,

$$
\mathrm{C}_{\mathrm{c}}=\frac{\Delta \mathrm{V}_{\mathrm{c}}}{\Delta \mathrm{P}_{\mathrm{c}}}
$$

Then,

$$
\Delta \mathrm{V}_{\mathrm{c}}=\mathrm{C}_{\mathrm{c}} \Delta \mathrm{P}_{\mathrm{c}} .
$$

Therefore, in Equation (2), $\mathrm{FMD}_{\mathrm{c}}$ can be measured by the cuff-pressure changes due to cardiac pulsations $\left(\Delta \mathrm{P}_{\mathrm{c}}\right)$,

$$
\mathrm{FMD}_{\mathrm{c}}=\frac{\mathrm{C}_{\mathrm{c}} \Delta \mathrm{P}_{\mathrm{c}, \mathrm{H}}-\mathrm{C}_{\mathrm{c}} \Delta \mathrm{P}_{\mathrm{c}, \mathrm{B}}}{\mathrm{C}_{\mathrm{c}} \Delta \mathrm{P}_{\mathrm{c}, \mathrm{B}}}=\frac{\Delta \mathrm{P}_{\mathrm{c}, \mathrm{H}}-\Delta \mathrm{P}_{\mathrm{c}, \mathrm{B}}}{\Delta \mathrm{P}_{\mathrm{c}, \mathrm{B}}},
$$

where $\Delta \mathrm{P}_{\mathrm{c}, \mathrm{B}}, \Delta \mathrm{P}_{\mathrm{c}, \mathrm{H}}$ are the changes in the cuff pressure due to the pulsatile nature of arterial blood pressure (oscillating between the systolic and diastolic values) during the baseline and hyperemia reaction phases. To reduce the effect of motion artifacts on $\Delta \mathrm{P}_{\mathrm{c}, \mathrm{H}}$, the cuff- pressure changes of three contiguous pulses are averaged as $\Delta \mathrm{P}_{\mathrm{c}, \mathrm{H}}$, which are manually selected in a $5 \mathrm{~s}$ interval centered at $\mathrm{D}_{\mathrm{H}, \max }$ happening time, for the hyperemic phase. Moreover, the median pulse corresponds to the maximal magnitudes of oscillation in cuff pressure due to arterial pulsation. Similarly, to increase the stability of $\Delta \mathrm{P}_{\mathrm{c}, \mathrm{B}}$, the cuff-pressure changes of three contiguous pulses with most coincident magnitudes are averaged as $\Delta \mathrm{P}_{\mathrm{C}, \mathrm{B}}$, which are manually selected in a $20 \mathrm{~s}$ interval preceding the ischemia stress, for the baseline phase.

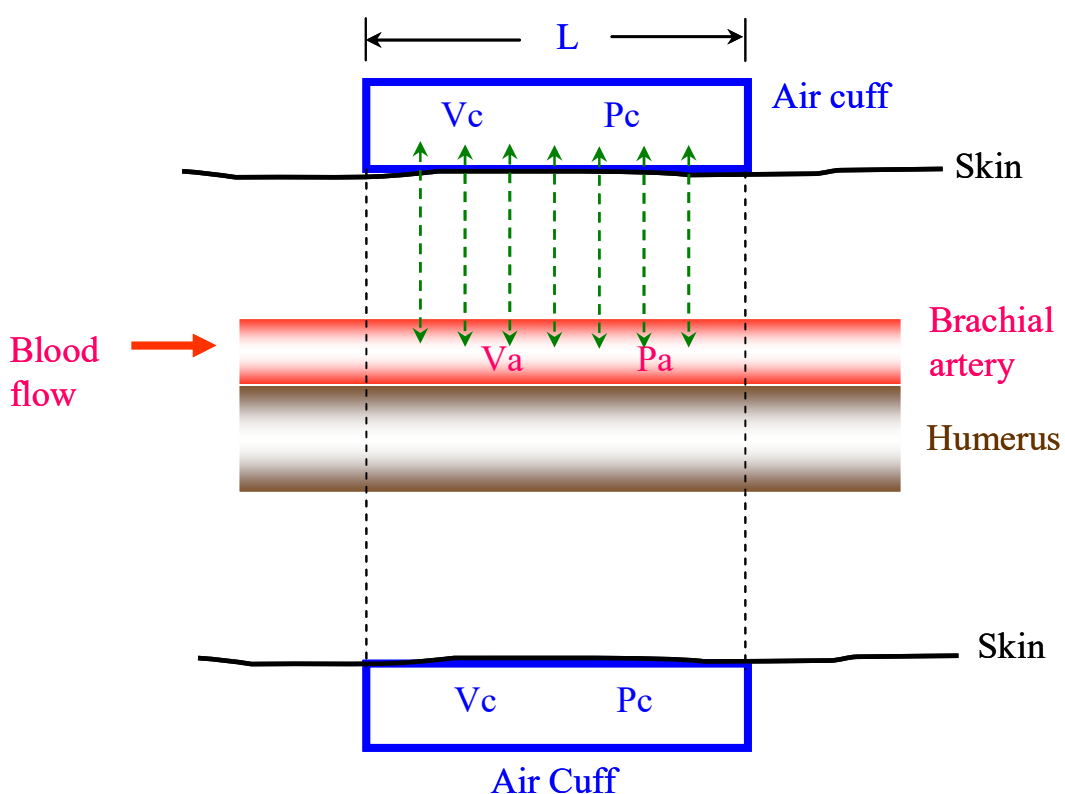

Figure 1. Schematic diagram of an air cuff bladder wrapped around an upper arm. $V_{a}$ and $P_{a}$ are the volume and pressure inside the brachial arterial segment $L$, and $V_{C}$ and $P_{C}$ are the volume and pressure of the cuff bladder, respectively. 


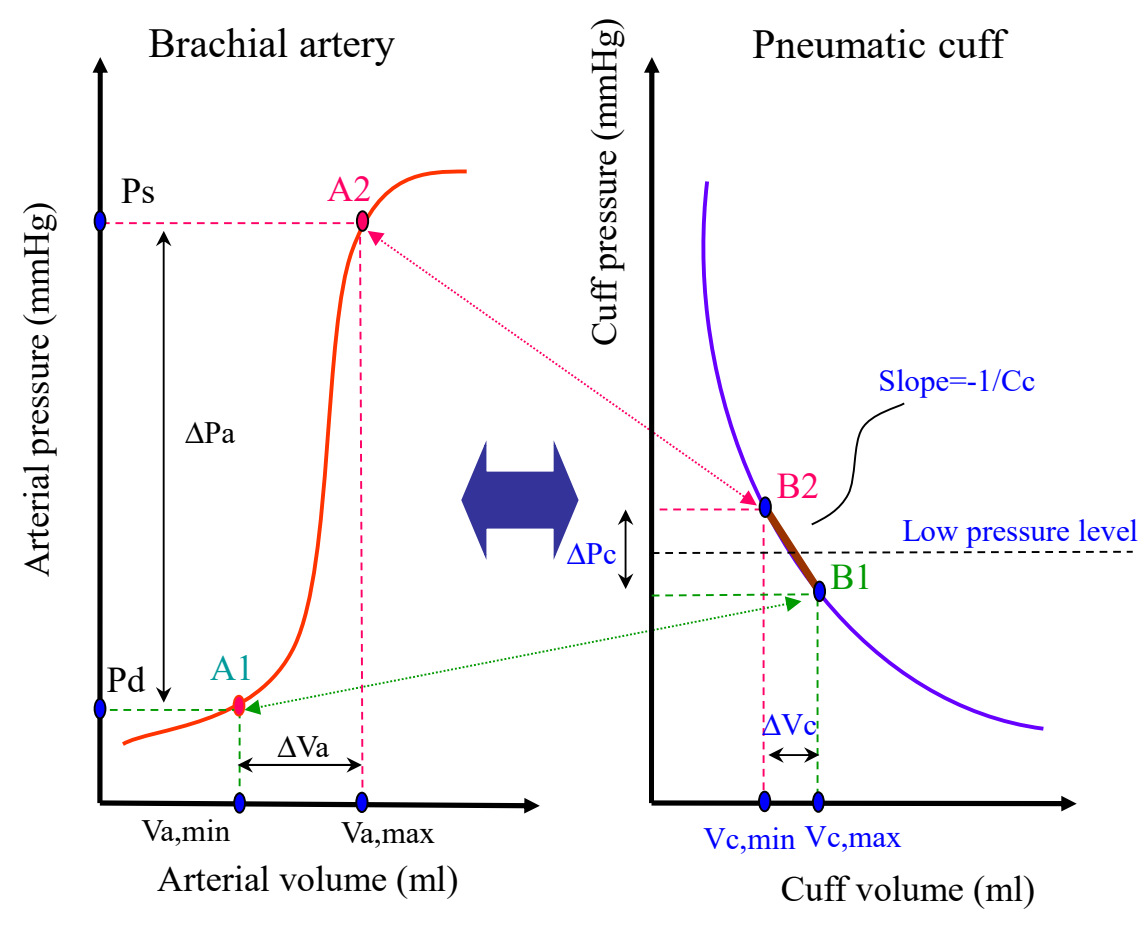

(a)

(b)

Figure 2. Interaction between the brachial artery and the cuff bladder: (a) relationship of the artery pressure to volume, (b) relationship of the cuff pressure to volume. $\Delta \mathrm{V}_{\mathrm{a}}$ causes an effect on the cuff bladder, $\Delta \mathrm{V}_{\mathrm{C}}$. When $\Delta \mathrm{P}_{\mathrm{C}}$ and $\Delta \mathrm{V}_{\mathrm{C}}$ are very small, the compliance $\left(\mathrm{C}_{\mathrm{C}}\right)$ is defined as the ratio of $\Delta \mathrm{V}_{\mathrm{C}}$ and $\Delta \mathrm{P}_{\mathrm{C}}$.

\subsection{Relation between $F M D_{c}$ and $F M D_{u}$}

According to Equation (2), $\Delta \mathrm{V}_{\mathrm{c}}$ is replaced with $\alpha \Delta \mathrm{V}_{\mathrm{a}}$. Then, in Equation (2), $\mathrm{FMD}_{\mathrm{c}}$ is changed to the ratio of the volume changes of a segment artery due to cardiac pulsations before and after the ischemic stress,

$$
\mathrm{FMD}_{\mathrm{c}}=\frac{\alpha \Delta \mathrm{V}_{\mathrm{a}, \mathrm{H}}-\alpha \Delta \mathrm{V}_{\mathrm{a}, \mathrm{B}}}{\alpha \Delta \mathrm{V}_{\mathrm{a}, \mathrm{B}}}=\frac{\Delta \mathrm{V}_{\mathrm{a}, \mathrm{H}}-\Delta \mathrm{V}_{\mathrm{a}, \mathrm{B}}}{\Delta \mathrm{V}_{\mathrm{a}, \mathrm{B}}},
$$

where $\Delta \mathrm{V}_{\mathrm{a}, \mathrm{B}}$ and $\Delta \mathrm{V}_{\mathrm{a}, \mathrm{H}}$ are the volume changes of the artery for a pulse before and after the ischemic stress. If the width of the cuff is $\mathrm{L}$, the segment length of the artery is also L. When the segmented artery is considered to be cylindrical, the $\Delta \mathrm{V}_{\mathrm{a}}$ is calculated with the diameters of the artery under the systolic and diastolic blood pressures and $\mathrm{L}$ in Equation (10). Then, $\mathrm{FMD}_{\mathrm{c}}$ is derived as

$$
\mathrm{FMD}_{\mathrm{C}}=\frac{\left[\mathrm{L} \pi\left(\frac{\mathrm{D}_{\mathrm{H}, \text { max }}}{2}\right)^{2}-\mathrm{L} \pi\left(\frac{\mathrm{D}_{\mathrm{H}, \text { min }}}{2}\right)^{2}\right]-\left[\mathrm{L} \pi\left(\frac{\mathrm{D}_{\mathrm{B}, \max }}{2}\right)^{2}-\mathrm{L} \pi\left(\frac{\mathrm{D}_{\mathrm{B}, \text { min }}}{2}\right)^{2}\right]}{\mathrm{L} \pi\left(\frac{\mathrm{D}_{\mathrm{B}, \text { max }}}{2}\right)^{2}-\mathrm{L} \pi\left(\frac{\mathrm{D}_{\mathrm{B}, \text { min }}}{2}\right)^{2}},
$$

where $\mathrm{D}_{\mathrm{H}, \max }$ and $\mathrm{D}_{\mathrm{H} \text {,min }}$ are the diameters of the artery under the systolic and diastolic blood pressures when the volume change of the artery is $\Delta \mathrm{V}_{\mathrm{a}, \mathrm{H}} ; \mathrm{D}_{\mathrm{B}, \max }$ and $\mathrm{D}_{\mathrm{B}, \text { min }}$ are the diameters of the artery under the systolic and diastolic blood pressures when the volume change of the artery is $\Delta \mathrm{V}_{\mathrm{a}, \mathrm{B}}$. The factor $\frac{\mathrm{L} \pi}{4}$ in the denominator and numerator is deleted,

$$
\mathrm{FMD}_{\mathrm{c}}=\frac{\left[\left(\mathrm{D}_{\mathrm{H}, \text { max }}\right)^{2}-\left(\mathrm{D}_{\mathrm{H}, \text { min }}\right)^{2}\right]-\left[\left(\mathrm{D}_{\mathrm{B}, \text { max }}\right)^{2}-\left(\mathrm{D}_{\mathrm{B}, \text { min }}\right)^{2}\right]}{\left(\mathrm{D}_{\mathrm{B}, \max }\right)^{2}-\left(\mathrm{D}_{\mathrm{B}, \text { min }}\right)^{2}} .
$$


For simplicity, we delete $\mathrm{D}_{\mathrm{H}, \mathrm{min}}$ and $\mathrm{D}_{\mathrm{B}, \mathrm{min}}$. Then, $\mathrm{FMD}_{\mathrm{c}}$ can be expressed as

$$
\mathrm{FMD}_{\mathrm{c}}=\frac{\left(\mathrm{D}_{\mathrm{H}, \max }\right)^{2}-\left(\mathrm{D}_{\mathrm{B}, \max }\right)^{2}}{\left(\mathrm{D}_{\mathrm{B}, \text { max }}\right)^{2}-\left(\mathrm{D}_{\mathrm{B}, \min }\right)^{2}} .
$$

When $\left(\mathrm{D}_{\mathrm{B}, \mathrm{min}}\right)^{2}$ is deleted from the denominator of Equation (12), an inequality formula associated with $\mathrm{FMD}_{\mathrm{C}}$ is

$$
\mathrm{FMD}_{\mathrm{c}}>\frac{\left(\mathrm{D}_{\mathrm{H}, \max }\right)^{2}-\left(\mathrm{D}_{\mathrm{B}, \max }\right)^{2}}{\left(\mathrm{D}_{\mathrm{B}, \max }\right)^{2}} .
$$

We know that

$$
\begin{aligned}
& \frac{A^{2}-B^{2}}{B^{2}}= \frac{A^{2}-2 A B+B^{2}}{B^{2}}+\frac{2 A B-2 B^{2}}{B^{2}} \\
&=\left(\frac{A-B}{B}\right)^{2}+2 \frac{A-B}{B} .
\end{aligned}
$$

Thus, we have an inequality formula relating to $\mathrm{FMD}_{\mathrm{c}}$ and $\mathrm{FMD}_{\mathrm{u}}$,

$$
\mathrm{FMD}_{\mathrm{c}}>\left(\mathrm{FMD}_{\mathrm{u}}\right)^{2}+2 \mathrm{FMD}_{\mathrm{u}}
$$

\subsection{Experimental Protocol and Measurement}

The study recruited 51 subjects, consisting of 13 patients with hypertension (patient group: 12 males and 1 female) and 38 healthy participants (control group: 28 males and 10 females). Table 1 shows the basic information of the subjects and their statistical analysis. The patient group had an average age of $62.5 \pm 14.1$ (mean \pm standard deviation) years, weight of $69.5 \pm 7.9 \mathrm{~kg}$, height of $162.6 \pm 5.3 \mathrm{~cm}$, systolic blood pressure (SBP) of $144 \pm 15 \mathrm{mmHg}$, diastolic blood pressure (DBP) of $84 \pm 10 \mathrm{mmHg}$, and body mass index (BMI) of $26.3 \pm 2.7$. The control group had an average age of $22.5 \pm 4.8$ years, weight of $72.3 \pm 23.3 \mathrm{~kg}$, height of $166.5 \pm 20.9 \mathrm{~cm}, \mathrm{SBP}$ of $122 \pm 13 \mathrm{mmHg}$, DBP of $75 \pm 10 \mathrm{mmHg}$, and $\mathrm{BMI}$ of $23.8 \pm 4.2$. A two-tailed unpaired $t$-test was used to compare the changes in the basic data between the patient and the control groups. A p-value of 0.05 or less was considered statistically significant. Between the two groups, there were significant differences in the age, SBP, DBP, and BMI. The clinical trial was agreed by the Institutional Review Board of the E-DA Hospital, Kaohsiung, Taiwan (no. EMRP61101N), and informed consent was received from each subject before the clinical trial began. The temperature inside the outpatient clinic room was maintained at $25^{\circ} \mathrm{C}$ by means of an air conditioner.

Table 1. Basic information of 51 subjects and their statistical analysis.

\begin{tabular}{ccccc}
\hline & $\begin{array}{c}\text { Subjects } \\
\mathbf{( N = 5 1 )}\end{array}$ & $\begin{array}{c}\text { Control Group } \\
\mathbf{( N = 3 8 )}\end{array}$ & $\begin{array}{c}\text { Patient Group } \\
\mathbf{( N = 1 3 )}\end{array}$ & $p$-Value \\
\hline Weight $(\mathrm{kg})$ & $71.6 \pm 20.5$ & $72.3 \pm 23.3$ & $69.5 \pm 7.9$ & 0.526 \\
Height $(\mathrm{cm})$ & $165.5 \pm 18.3$ & $166.5 \pm 20.9$ & $162.6 \pm 5.3$ & 0.295 \\
Age (years) & $32.7 \pm 19.4$ & $22.5 \pm 4.8$ & $62.5 \pm 14.1$ & $<0.001$ \\
SBP $(\mathrm{mmHg})$ & $127.7 \pm 16.6$ & $122.3 \pm 13.4$ & $143.5 \pm 15.2$ & $<0.001$ \\
DIA $(\mathrm{mmHg})$ & $77.5 \pm 10.9$ & $75.3 \pm 10.4$ & $83.9 \pm 10.2$ & 0.016 \\
BMI $\left(\mathrm{kg} / \mathrm{m}^{2}\right)$ & $24.5 \pm 4$ & $23.8 \pm 4.2$. & $26.3 \pm 2.7$ & 0.021 \\
\hline
\end{tabular}

The experimental protocol is shown in Figure 3. Each subject in supine position was required to take at least a $5 \mathrm{~min}$ rest to make physiological parameters stable before the measurement began. During the baseline condition (first $30 \mathrm{~s}$ ), the diameter of the left brachial artery was measured by a high frequency ultrasound system (Philips, iE33, Netherlands). Then, the sphygmomanometer cuff wrapped around the upper left arm was inflated to $40 \mathrm{mmHg}$ to measure the cuff-pressure signal (second $30 \mathrm{~s}$ ). After finishing the baseline measurement, the sphygmomanometer cuff was inflated to a pressure level of $\mathrm{SBP}+50 \mathrm{mmHg}$ to perform an ischemic stress for at least $5 \mathrm{~min}$. Then, we applied the 
synchronous measurement for the BAUS and cuff method during the hyperemic reaction because the response of vasodilation after the ischemic stress will usually happen within $60 \mathrm{~s}$. Moreover, subjects felt very uncomfortable during the ischemic stress. According to the protected right of subjects, the FMD measurement was very hard to do twice at the same time. Thus, when the cuff pressure was rapidly deflated from systolic $+50 \mathrm{mmHg}$ to $40 \mathrm{mmHg}$ to measure the cuff-pressure signal, the diameter of the brachial artery was again measured through the BAUS method at the same time. During the whole measurement period, two PPG sensors were placed on the left and right index fingers to measure the PPG signals. Moreover, a lead-I ECG signal was simultaneously recorded to identify the cycles of heart beats.

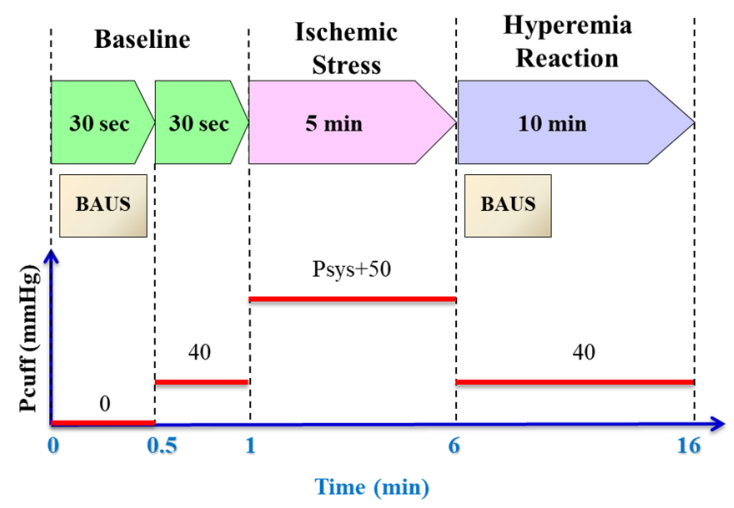

Figure 3. The experimental protocol consists of a $30 \mathrm{~s}$ baseline, $5 \mathrm{~min}$ ischemic stress and $10 \mathrm{~min}$ hyperemia reaction.

\subsection{Data Measurement and Processing}

The cuff pressure, the PPG signals and the Lead-I ECG signals were acquired by the MP150 system (BIOPAC System, Inc., Goleta, California, USA). The resolution of the digital signals was 12 bits, and the sampling rate was $1000 \mathrm{~Hz}$. A two-order Butterworth prototype was used to design the high- and low-pass filters with cut-off frequencies of $0.5 \mathrm{~Hz}$ and $40 \mathrm{~Hz}$, respectively. The blood pressure monitor used in the study was OMRON HEM-7320 (OMRON, Inc., Kyoto, Japan), and the cuff bladder was OMRON HEM-FM31 (OMRON, Inc., Kyoto, Japan), which fitted arm circumferences from $17 \mathrm{~cm}$ to $36 \mathrm{~cm}$. The band-pass filter was used to reduce low-frequency components (mainly including DC components and baseline drift) and high-frequency components (mainly caused by $60-\mathrm{Hz}$ powerline interference). The brachial artery diameter was measured at the same time during a cardiac cycle, optimally achieved using ECG gating during image acquisition. The onset of the R-wave was used to identify end diastole, and the peak of the T-wave reproducibly identified end systole. Thus, in this study, the minimum diameter of brachial artery in the cardiac cycle was determined at the onset of R-wave, and the maximum diameter of brachial artery in the cardiac cycle was determines at the onset of T-wave. In the baseline phase, continuous $30 \mathrm{~s}$ ultrasound image frames were recorded, and continuous $60 \mathrm{~s}$ ultrasound image frames were recorded in the hyperemia reaction phase. To increase the stability of $\mathrm{D}_{\mathrm{B}, \mathrm{max}}$, the maximum diameters of three contiguous heartbeats with the most coincident values were averaged as the $D_{B, \max }$, which were manually selected in a $10 \mathrm{~s}$ interval preceding the ischemia for the baseline phase. Moreover, the time course of maximum diameters manually selected in a $30 \mathrm{~s}$ interval centered at $30 \mathrm{~s}$ after the end of the ischemia stress was used to determine the $\mathrm{D}_{\mathrm{H}, \mathrm{max}}$ for the hyperemic phase. The operators were not blind in choosing the ultrasound images or the signal pulses in the study. A standard pulse wave has an evident exponential decay in diastolic duration [21], and there was limited difference between the systolic starting point and the diastolic ending point. Data processing was mostly carried out with AcqKnowledge Software 3.9 (BIOPAC System, Inc., Goleta, CA, USA). 


\section{Experimental Results}

\subsection{Typical Recording}

Figure 4 shows three synchronous signals, including a cuff-pressure signal and two PPG signals for subject \#37 in the control group during the FMD measurement. Figure 4a is the cuff-pressure signal (i.e., the ac components) after passing through the digital highpass filters, and Figure $4 \mathrm{~b}, \mathrm{c}$ are the PPG signals measured from the left and right hands, respectively. When the cuff pressure was rapidly inflated to sys $+50 \mathrm{mmHg}$ or rapidly deflated to $40 \mathrm{mmHg}$, the transient response of the digital high-pass filter affected the baseline of the cuff pressure signal. Thus, the baseline of the cuff pressure signal in the ischemic stress and hyperemic reaction is shifted up and down. The PPG signal of the left hand is used to measure the FMD ratio, and the PPG signal of the right hand is compared to the hyperemia reaction of the left hand. In the ischemic stress phase, the cuff-pressure signal has some noise because the compliance of the cuff bladder at high pressure is very low. Moreover, because the blood flow of the right hand is not occluded, the PPG signal shows the pulse waves in the ischemic stress phase. In contrast, the pulse waves do not appear in the PPG signal of left hand in this phase. These results demonstrate that the blood flow of the left hand is occluded.

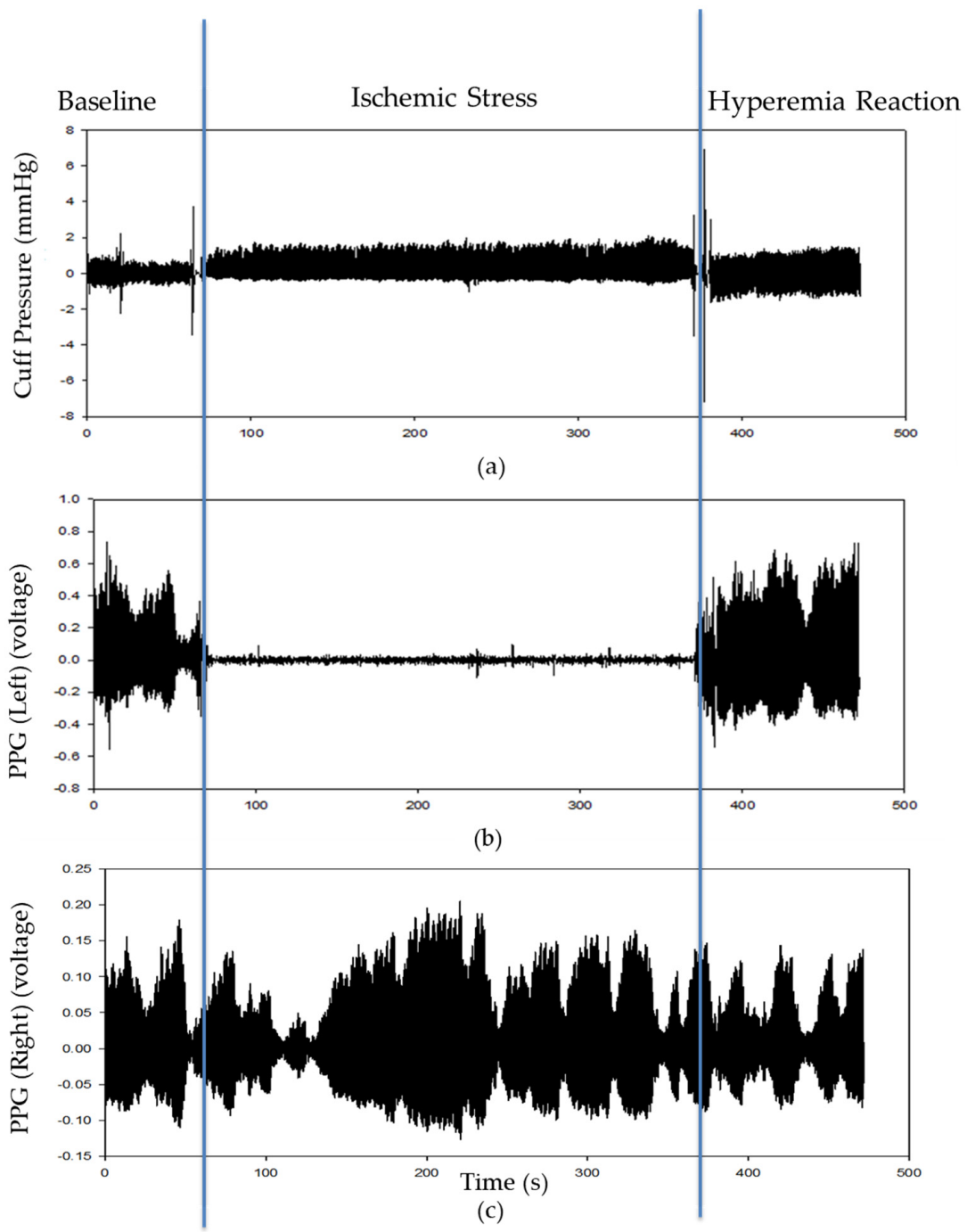

Figure 4. The cuff-pressure signal and PPG signals for subject \#37 during FMD measurement, (a) cuff-pressure signal after passing through the digital high-pass filters, (b) PPG signal of left hand, PPG (Left), (c) PPG signal of right hand, PPG (Right). 
Figure 5 shows the diameters of the artery measured by BAUS before and after the ischemic stress for subject \#37. Because the arterial intima in the image was not clear for all of the subjects, we detected the arterial adventitial layer to calculate the diameter under the systolic cycle with the synchronous ECG. We manually marked the position of maximum diameter in the baseline phase (recording $30 \mathrm{~s}$ ) and hyperemia reaction phase (recording $60 \mathrm{~s})$.

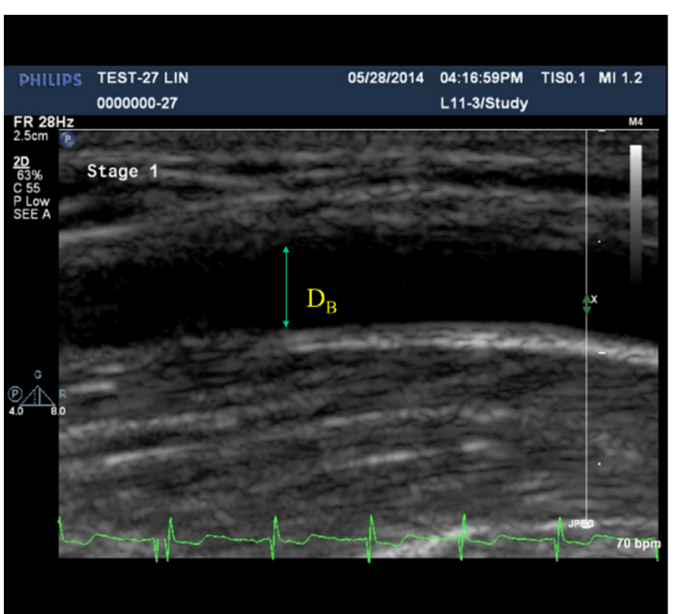

(a)

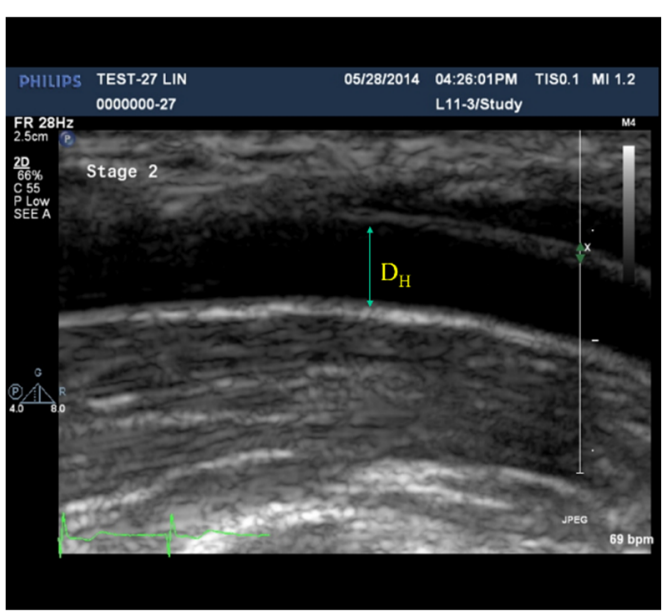

(b)

Figure 5. (a) The BAUS image used to measure the diameter $\left(D_{B}\right)$ before the ischemic stress, $(\mathbf{b})$ the image by BAUS used to measure the diameter $\left(\mathrm{D}_{\mathrm{H}}\right)$ in the hyperemia reaction phase.

\subsection{FMD Ratios Measurement}

Table 2 shows the FMD values measured by the BAUS, PPG, and cuff methods in the control and patient groups, which are defined in Equations (1), (3), and (8). A two-tailed unpaired $t$-test was used to test whether a significant difference exists. A $p$-value of 0.05 or less was considered statistically significant. In the control group, the $\mathrm{FMD}_{\mathrm{c}}$ mean was the largest and the $\mathrm{FMD}_{\mathrm{u}}$ mean was the smallest. $\mathrm{FMD}_{\mathrm{u}}$ and $\mathrm{FMD}_{\mathrm{c}}$ are significantly different in the control and patient groups. However, although the $\mathrm{FMD}_{\mathrm{p}}$ and $\mathrm{FMD}_{\mathrm{u}}$ means are the largest and smallest in the patient group, $\mathrm{FMD}_{\mathrm{p}}$ does not show a significant difference between the two groups. Thus, we did not consider the FMD $\mathrm{p}$ results. According to Table 2, in both the control and the patient group, the relation between $\mathrm{FMD}_{\mathrm{c}}$ and $\mathrm{FMD}_{\mathrm{u}}$ are satisfied with Equation (15). Figure 6 shows the linear regression between $\mathrm{FMD}_{\mathrm{u}}$ and $\mathrm{FMD}_{\mathrm{c}}$ for all subjects, with a correlation coefficient $(\mathrm{R})$ of 0.662 .

Table 2. The results (mean \pm standard deviation) of $\mathrm{FMD}_{\mathrm{u}} \cdot \mathrm{FMD}_{\mathrm{p}}$ and $\mathrm{FMD}_{\mathrm{c}}$ in control and patient groups.

\begin{tabular}{|c|c|c|c|c|c|c|}
\hline & \multicolumn{2}{|c|}{$\mathrm{FMD}_{\mathrm{u}} \%$} & \multicolumn{2}{|c|}{$\mathrm{FMD}_{\mathrm{p}} \%$} & \multicolumn{2}{|c|}{ FMD $_{c} \%$} \\
\hline & $\begin{array}{l}\text { Control } \\
(\mathrm{N}=38)\end{array}$ & $\begin{array}{c}\text { Patient } \\
(N=13)\end{array}$ & $\begin{array}{l}\text { Control } \\
(\mathrm{N}=38)\end{array}$ & $\begin{array}{l}\text { Patient } \\
(N=13)\end{array}$ & $\begin{array}{l}\text { Control } \\
(\mathrm{N}=38)\end{array}$ & $\begin{array}{l}\text { Patient } \\
(\mathrm{N}=13)\end{array}$ \\
\hline $\mathrm{M} \pm \mathrm{SD}$ & $(8.1 \pm 4.3) \%$ & $(4.5 \pm 1.1) \%$ & $(93.4 \pm 34.4) \%$ & $(84.4 \pm 44.4) \%$ & $(121.6 \pm 48.6) \%$ & $(55.2 \pm 22.8) \%$ \\
\hline$p$-value & \multicolumn{2}{|c|}{0.040} & \multicolumn{2}{|c|}{0.06} & \multicolumn{2}{|c|}{$<0.001$} \\
\hline
\end{tabular}

M: mean, SD: standard deviation.

Then, we detailed the FMD ratio parameters, measured by the BAUS and cuff methods in Tables 3 and 4. A two-tailed unpaired $t$-test was used to test whether a significant difference exists. A $p$-value of 0.05 or less was considered statistically significant. In Table 3 , $\mathrm{D}_{\mathrm{B}, \max }, \mathrm{D}_{\mathrm{B}, \min }, \mathrm{D}_{\mathrm{H}, \max }$, and $\mathrm{D}_{\mathrm{H} \text {,min }}$ are measured by BAUS for the control and patient groups in the baseline and hyperemia reaction phases. The mean values of such four terms measured from the health subjects all are significantly smaller than those from the patients, respectively. According to Equation (1), $\mathrm{FMD}_{\mathrm{u}}$ is assessed merely by $\mathrm{D}_{\mathrm{B}, \max }$ and 
$\mathrm{D}_{\mathrm{H}, \max }$. Moreover, $\mathrm{D}_{\mathrm{B}, \min }$ and $\mathrm{D}_{\mathrm{H} \text {,min }}$ do not have a significant difference between the control and patient groups. In Table $4, \Delta \mathrm{P}_{\mathrm{c}, \mathrm{B}}$ and $\Delta \mathrm{P}_{\mathrm{C}, \mathrm{H}}$ are measured by the cuff method for the control and patient groups in baseline and hyperemia reaction phases. Both $\Delta \mathrm{P}_{\mathrm{C}, \mathrm{B}}$ and $\Delta \mathrm{P}_{\mathrm{C}, \mathrm{H}}$ measured from the healthy subjects appear significantly smaller than those from the patients, respectively.

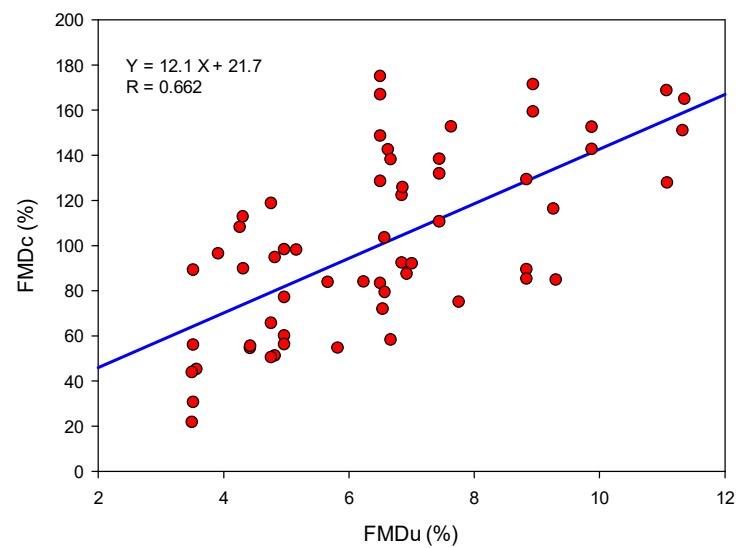

Figure 6. The linear regression between $\mathrm{FMD}_{\mathrm{u}}$ and $\mathrm{FMD}_{\mathrm{c}}$ with a correlation coefficient (R) of 0.662.

Table 3. The results (mean \pm standard deviation) of $\mathrm{D}_{\mathrm{B}, \max }, \mathrm{D}_{\mathrm{H}, \max }, \mathrm{D}_{\mathrm{B}, \min }$, and $\mathrm{D}_{\mathrm{H}, \min }$ measured by BAUS.

\begin{tabular}{ccccccc}
\hline & $\mathbf{D}_{\mathbf{B}, \max }(\mathbf{c m})$ & $\mathbf{D}_{\mathbf{H}, \max }(\mathbf{c m})$ & $p$-Value & $\mathbf{D}_{\mathbf{B}, \min }(\mathbf{c m})$ & $\mathbf{D}_{\mathbf{H}, \min }(\mathbf{c m})$ & $p$-Value \\
\hline Control & $0.323 \pm 0.057$ & $0.348 \pm 0.060$ & 0.001 & $0.297 \pm 0.055$ & $0.321 \pm 0.056$ & 0.116 \\
Patient & $0.400 \pm 0.057$ & $0.422 \pm 0.220$ & 0.002 & $0.350 \pm 0.052$ & $0.380 \pm 0.052$ & 0.302 \\
$p$-value & 0.001 & 0.004 & & 0.018 & 0.015 & \\
\hline
\end{tabular}

Table 4. The results (mean \pm standard deviation) of $\Delta \mathrm{P}_{\mathrm{c}, \mathrm{B}}$ and $\Delta \mathrm{P}_{\mathrm{c}, \mathrm{H}}$ measured by the cuff method.

\begin{tabular}{ccc}
\hline & $\left.\boldsymbol{\Delta} \mathbf{P}_{\mathbf{c}, \mathbf{B}} \mathbf{( m m H g}\right)$ & $\left.\boldsymbol{\Delta} \mathbf{P}_{\mathbf{c}, \mathbf{H}} \mathbf{( m m H g}\right)$ \\
\hline Control & $1.441 \pm 0.75$ & $3.0 \pm 1.48$ \\
Patient & $2.302 \pm 1.83$ & $3.58 \pm 2.73$ \\
$p$-value & 0.002 & 0.036 \\
\hline
\end{tabular}

\section{Discussion}

For FMD examination, the BAUS and PAT methods are the most utilized techniques in clinical practice. Kuvin et al. compared the performance of PAT and BAUS techniques for assessing peripheral vascular reactivity and found that the correlation coefficient between the PAT-based FMD\% (defined as the ratio of finger pulse wave amplitude during reactive hyperemia relative to the baseline) and BAUS-based FMD\% (defined as the ratio of the brachial artery diameter during reactive hyperemia relative to the baseline) for 54 men and 35 women was 0.55 [16]. They also indicated that subjects in the lowest BAUS-based FMD\% quartile had the lowest PAT-based FMD\%, whereas subjects in the highest BAUS-based FMD $\%$ quartile had the highest PAT-based FMD $\%$ ( $p<0.001$ for trend). In the study by Kuvin et al., a ring-type pneumatic cuff is inflated to a proper pressure level (usually below diastolic pressure) for measurement of finger arterial pulse wave amplitude. In the present study, an air cuff is applied to sense the change in brachial arterial volume of one segment wrapped by the cuff, and the changes in the cuff pressure during the baseline and hyperemic reaction are then used to assess $\mathrm{FMD}_{\mathrm{c}} \%$. The present results show a correlation coefficient of 0.662 between $\mathrm{FMD}_{\mathrm{u}} \%$ and $\mathrm{FMD}_{\mathrm{c}} \%$. The study by Kuvin et al. compares the hyperemic reaction of fingers with PAT and that of brachial arteries with BAUS, while our study compares $\mathrm{FMD}_{\mathrm{c}} \%$ and $\mathrm{FMD}_{\mathrm{u}} \%$ of brachial arteries with the cuff method and BAUS, respectively. It is worth noting that the trend of $\mathrm{FMD}_{\mathrm{u}} \%$ and $\mathrm{FMD}_{\mathrm{c}} \%$ as shown in Figure 6 is better than that in the study of Kuvin et al. [16]. 
Pressure waves of peripheral arteries have been used to assess the FMD in some studies. Wu et al. proposed conducting FMD measurements using a cuff bladder placed on the wrist and used ensemble empirical model decomposition to remove the noise of the pressure waves [22,23]. In any case, BAUS, PAT, and the method used in the study by Wu et al. all utilized a sphygmomanometer cuff to induce an episode of ischemic stress. Thus, Liu et al. proposed a cuff method which used only a sphygmomanometer cuff to cause an ischemic stress and to record the pressure waves [18,19]. They studied the change in $\mathrm{FMD}_{\mathrm{c}}$ in the menstrual cycle for 26 volunteer females. The results confirmed those found in the study of Hashimoto et al. [18]. However, the weakness of their study was that they did not compare $\mathrm{FMD}_{\mathrm{c}}$ with $\mathrm{FMD}_{\mathrm{u}}$. Thus, although they found that the values of FMD ratio measured by the cuff method were larger than the results measured by BAUS, they could not explain this phenomenon. In the work, we derived an inequality formula regarding $\mathrm{FMD}_{\mathrm{c}}$ and $\mathrm{FMD}_{\mathrm{u}}$ from the cuff model. In Table 2, we find that $\mathrm{FMD}_{\mathrm{c}}$ is not only larger than $\mathrm{FMD}_{\mathrm{u}}$ but also larger than twofold of $\mathrm{FMD}_{\mathrm{u}}$. This is consistent with Equation (15).

According to our previous study [19], the cuff model was shown by an exponential function, as shown in Figures 5 and 6. We can find that the compliance around the $40 \mathrm{mmHg}$ is close to a constant. Moreover, according to the study by Maltz et al., a cuff wrapped the upper arm is inflated to a low pressure level (for example, $40 \mathrm{mmHg}$ ), the perturbation $\left(\Delta \mathrm{V}_{\mathrm{c}}\right)$ in the cuff volume due to the arterial pulse is much smaller than the cuff volume $\left(V_{c}\right)$ (i.e., $\Delta V_{c}$ « Vc) [24]. Then, the cuff compliance at such transmural pressure $(40 \mathrm{mmHg})$ approximates a linear relationship with a slope $-V_{c} / P_{c}$, and we may assume that $\Delta \mathrm{Pc} \propto \Delta \mathrm{Vc}$. Consequently, a low-pressure cuff bladder can be considered as a "convenient sensor" for the FMD measurement for brachial arteries, since the cuff bladder has a constant compliance with the small changes in volume and pressure, as shown in Figures 1 and 2. This characteristic, constant compliance, plays an important role in the interaction between the brachial artery and cuff bladder for sensing the change in the volume of one-segment artery. It is worth noting that the values of $\mathrm{FMD}_{\mathrm{c}}$ obtained by the cuff method are significantly greater than those of $\mathrm{FMD}_{\mathrm{u}}$ obtain by BAUS in either the control or the patient group, as shown in Table 2. The finding directly reflects Equation (15) proposed in the study. Additionally, the proposed cuff method may be further implemented in an automated blood pressure measurement device for daily assessment of FMD .

In this study, we also measured $\mathrm{FMD}_{\mathrm{p}}$ with a PPG probe that did not utilize the PAT system. In Table 2, the mean of $\mathrm{FMD}_{\mathrm{p}}$ in the control group was larger than the mean in the patient group, but they do not have significant differences. This result means that we cannot deny that the performance of PAT is worse than that of the cuff method. The change in pulse amplitude in PPG, following ischemic stress, represents an integrated vascular response, following the release of several substances, including endotheliumdependent and -independent vasodilation, and overall microvascular function [14]. Thus, the reliability and stability of the FMD ratio, measured from the arteries, is lower than those measured from the brachial artery $[25,26]$.

In Table 3, the age, systolic pressure, diastolic pressure, and body mass index between patient and control groups were all significantly different. Moreover, the average age of patients, being 62.5 years old, was higher than the average age of the healthy subjects, being 22.5 years. We thought that pathogenesis could explain this result. Vascular endothelial dysfunction is an initial stage of atherosclerosis, and atherosclerosis develops with age to become more serious [27]. Thus, the appearance of maximal vessel dilation could be an early sign of vascular endothelial dysfunction. When the vessel has serious endothelial dysfunction, the change in vascular diameter after an ischemic stress is very low and leads to a lower FMD\%.

\section{Conclusions}

The contribution of this study is that we explain the interaction between the volume changes in the artery and cuff bladder due to cardiac pulsations under different transmural pressures. When the cuff-volume change due to cardiac pulsation is replaced with the 
cuff-pressure change, $\mathrm{FMD}_{\mathrm{c}}$ can be measured with the cuff-pressure change before and after ischemic stress. Then, we can theoretically derive the inequality formula of $\mathrm{FMD}_{\mathrm{c}}$ and $\mathrm{FMD}_{\mathrm{u}}$ and verify this inequality with the experimental data measured from fifty-one subjects. However, identifying the sensitivity and diagnostic threshold of $\mathrm{FMD}_{\mathrm{c}}$ is an issue for further study in the future.

Author Contributions: Conceptualization, J.-J.W. and S.-H.L.; methodology, S.-H.L. and Y.-H.P.; software, Y.-H.P.; validation, W.-K.T.; writing—original draft preparation, S.-H.L. and J.-J.W.; writingreview and editing, S.-H.L. and W.C. All authors have read and agreed to the published version of the manuscript.

Funding: This research was funded by the Ministry of Science and Technology under grants MOST 109-2221-E-324-002-MY2 and MOST 108-2221-E-214-007-MY3.

Institutional Review Board Statement: The clinical trial was agreed by the Institutional Review Board of the E-DA Hospital, Kaohsiung, Taiwan (no. EMRP61101N).

Informed Consent Statement: Informed consent was obtained from all subjects involved in the study.

Acknowledgments: The authors would like to acknowledge the E-Da hospital (Taiwan) for the administrative support.

Conflicts of Interest: The authors declare no conflict of interest.

\section{References}

1. Little, P.J.; Askew, C.D.; Xu, S.; Kamato, D. Endothelial dysfunction and cardiovascular disease: History and analysis of the clinical utility of the relationship. Biomedicines 2021, 9, 699. [CrossRef] [PubMed]

2. Costa, J.; Borges, M.; Oliveira, E.; Gouveia, M.; Carneiro, A.V. Incidence and prevalence of hypercholesterolemia in Portugal: A systematic review. Part 3. Rev. Port. Cardiol. 2003, 22, 829-836.

3. Sakakura, K.; Nakano, M.; Otsuka, F.; Ladich, E.; Kolodgie, F.D.; Virmani, R. Pathophysiology of atherosclerosis plaque progression. Heart Lung Circ. 2013, 22, 399-411. [CrossRef] [PubMed]

4. Bergheanu, S.C.; Bodde, M.C.; Jukema, J.W. Pathophysiology and treatment of atherosclerosis current view and future perspective on lipoprotein modification treatment. Neth. Heart J. 2017, 25, 231-242. [CrossRef] [PubMed]

5. Singh, R.B.; Mengi, S.A.; Xu, Y.-J.; Arneja, A.S.; Dhalla, N.S. Pathogenesis of atherosclerosis: A multifactorial process. Exp. Clin. Cardiol. 2002, 7, 40-53. [PubMed]

6. Smedby, O.; Johansson, J.; Molgaard, J.; Olsson, A.G.; Walldius, G.; Erikson, U. Predilection of atherosclerosis for the inner curvature in the femoral artery: A digitized angiography study. Arterioscler. Thromb. Vasc. Biol. 1995, 15, 912-917. [CrossRef]

7. Furchgott, R.F.; Zawadzki, J.V. The obligatory role of endothelial cells in the relaxation of arterial smooth muscle by acetylcholine. Nature 1980, 288, 373-376. [CrossRef]

8. Rassaf, T.; Feelisch, M.; Kelm, M. Circulating NO pool: Assessment of nitrite and nitroso species in blood and tissues. Free Radic. Biol. Med. 2004, 36, 413-422. [CrossRef]

9. Wu, H.D.; Katz, S.D.; Beniaminovitz, A.; Khan, T.; DiTullio, M.R.; Homma, S. Assessment of endothelium-mediated vasodilation of the peripheral circulation by transcutaneous ultrasonography and venous occlusion plethysmography. Heart Vessels 1999, 14, 143-148. [CrossRef]

10. Charakida, M.; Masi, S.; Luscher, T.F.; Kastelein, J.J.P.; Deanfield, J.E. Assessment of atherosclerosis: The role of flow-mediated dilatation. Eur. Heart J. 2010, 31, 2854-2861. [CrossRef]

11. Corretti, M.C.; Anderson, T.J.; Benjamin, E.J. Guidelines for the ultrasound assessment of endothelial-dependent flow-mediated vasodilation of the brachial artery: A report of the international brachial artery reactivity task force. J. Am. Coll. Cardiol. 2002, 39, 257-265. [CrossRef]

12. Ghiadoni, L.; Versari, D.; Giannarelli, C.; Faita, F.; Taddei, S. Non-invasive diagnostic tools for investigating endothelial dysfunction. Curr. Pharm. Des. 2008, 14, 3715-3722. [CrossRef] [PubMed]

13. Stadler, R.W.; Karl, W.C.; Lees, R.S. New methods for arterial diameter measurement from B-mode images. Ultrasound Med. Biol. 1996, 22, 25-34. [CrossRef]

14. Rubinshte, R.; Kuvin, J.T.; Soffler, M.; Lennon, R.J.; Lavi, S.; Nelson, R.E.; Pumper, G.M.; Lerman, L.O.; Lerman, A. Assessment of endothelial function by non-invasive peripheral arterial tonometry predicts late cardiovascular adverse events. Eur. Heart J. 2010, 31, 1142-1148. [CrossRef] [PubMed]

15. Hamburg, N.M.; Benjamin, E.J. Assessment of endothelial function using digital pulse amplitude tonometry. Trends Cardiovasc. Med. 2009, 19, 6-11. [CrossRef]

16. Kuvin, J.T.; Patel, A.R.; Sliney, K.A.; Pandian, N.G.; Sheffy, J.; Schnall, R.P.; Udelson, J.E. Assessment of peripheral vascular endothelial function with finger arterial pulse wave amplitude. Am. Heart J. 2003, 146, 168-174. [CrossRef] 
17. Hashimoto, M.; Akishita, M.; Eto, M.; Ishikawa, M.; Kozaki, K.; Toba, K.; Sagara, Y.; Taketani, Y.; Orimo, H.; Ouchi, Y. Modulation of endothelium-dependent flow-mediated dilatation of the brachial artery by sex and menstrual cycle. Circulation 1995, 92, 3431-3435. [CrossRef]

18. Liu, S.-H.; Wang, J.-J.; Cheng, D.-C.; Su, C.-H.; Lin, T.-H. Assessment of the endothelial function with changed volume of brachial artery by menstrual cycle. Biomed. Eng. 2016, 15, 106. [CrossRef]

19. Liu, S.-H.; Wang, J.-J.; Huang, K.-S. A New Oscillometry-Based Method for Estimating the Dynamic Brachial Artery Compliance under loaded conditions. IEEE Trans. Biomed. Eng. 2008, 55, 2463-2470. [CrossRef]

20. Liu, S.-H.; Wang, J.-J.; Cheng, D.-C. Non-invasive determination of the instantaneous brachial blood flow using the oscillometric method. Biomed. Tech. 2009, 54, 171-177. [CrossRef]

21. Liu, S.-H.; Lin, T.-H.; Cheng, D.-C.; Wang, J.-J. Assessment of stroke volume from brachial blood pressure using arterial characteristics. IEEE Trans. Biomed. Eng. 2015, 62, 2151-2157. [CrossRef] [PubMed]

22. Wu, H.-T.; Lee, C.-H.; Liu, A.-B.; Chung, W.-S.; Tang, C.-J.; Sun, C.-K.; Yip, H.-K. Arterial stiffness using radial arterial waveforms measured at the wrist as an indicator of diabetic control in the elderly. IEEE Trans. Biomed. Eng. 2011, 58, 243-252. [PubMed]

23. Wu, H.-T.; Lee, C.-H.; Sun, C.-K.; Hsu, J.-T.; Huang, R.-M.; Tang, C.-J. Arterial waveforms measured at the wrist as indicators of diabetic endothelial dysfunction in the elderly. IEEE Trans. Instrum. Meas. 2012, 61, 162-169. [CrossRef]

24. Maltz, J.S.; Tison, G.H.; Alley, H.F.; Budinger, T.F.; Owens, C.D.; Olgin, J. Measurement of brachial artery endothelial function using a standard blood pressure cuff. Physiol. Meas. 2015, 36, 2247-2268. [CrossRef] [PubMed]

25. Chowienczyk, P.J.; Kelly, R.P.; MacCallum, H.; Millasseau, S.C.; Andersson, T.L.; Gosling, R.G.; Änggård, E.E. Photoplethysmographic assessment of pulse wave reflection: Blunted response to endothelium-dependent beta2-adrenergic vasodilation in type II diabetes mellitus. J. Am. Coll. Cardiol. 1999, 34, 2007-2014. [CrossRef]

26. Bonetti, P.O.; Pumper, G.M.; Higano, S.T.; Holmes, D.R., Jr.; Kuvin, J.T.; Lerman, A. Noninvasive identification of patients witj early coronary atherosclerosis by assessment of digital reaction hyperemia. J. Am. Coll. Cardiol. 2004, 44, 2137-2141. [CrossRef]

27. Lekakis, J.; Abraham, P.; Balbarini, A.; Blann, A.; Boulanger, C.M.; Cockcroft, J.; Vlachopoulos, C. Methods for evaluating endothelial function: A position statement from the European society of cardiology working group on peripheral circulation. Eur. J. Cardiovasc. Prev. Rehabil. 2011, 18, 775-789. [CrossRef] 